\title{
The Perception of Sound and Its Influence in the Classroom
}

\author{
Sofia Reis and Nuno Correia \\ CITI and DI, Faculdade de Ciências e Tecnologia, Universidade Nova de Lisboa \\ 2829-516 Caparica - Portugal \\ se.reis@fct.unl.pt, nmc@i.fct.unl.pt
}

\begin{abstract}
In this paper we describe a game to assess if the quantitative and graphical perception of sound by students can influence how they behave in the classroom. The game captures sound and shows the sound wave or the frequency spectrum, integrated with an animated character, to students in real time. The quieter the students are the higher the score. A survey was conducted to teachers from an elementary and secondary school to determine if they considered that noise, caused by the students, was a problem. Most of the teachers considered that students make too much noise. All the classes where the game was tested became quieter, thus showing that when these students perceived, in a quantitative way, how much their behavior was disruptive they were more inclined to be quiet or, at least, to reduce the amount of noise.
\end{abstract}

Keywords: game, persuasive technology, noise, classroom.

\section{Introduction}

Students can develop several different types of work in the classroom. Sometimes the teacher may expose something to the students and need the whole class to keep quiet and listen to what is being explained. Other times, students engage in tasks where they have to talk to each other. Nevertheless, whatever the activity is, if the sound level is too high it will be difficult for people to listen to each other. Furthermore, excessive noise can disturb students in other classrooms. Even though classroom noise may have different sources, some internal and others external to the classroom, here the focus is on the noise caused by the students talking to each other.

Noisy classrooms have an adverse effect on students' learning and the strain on teachers' voices can result in illness, as is described in Section 2.

We developed a game that motivates students to make less noise in the classroom. Games have already been previously used to change people's behavior (Section 3). Our game, which is further described in Section 4, is populated by characters that are only happy in the silence. If students are quiet they will gain more points. The game is, therefore, an incentive for students to change their behavior via an increased awareness of how much noise they are causing. The game was tested in an elementary and secondary school. Before the game was tested we assessed the school's initial situation to determine the teachers' and students' views about noise in the classroom 
(Section 5). The game's test results are presented in Section 6. Finally, the conclusions and future work are in Section 7.

\section{Effects of Classroom Noise on Students and Teachers}

Classroom noise is detrimental to students' learning and can result in several adverse consequences. Noise decreases word recognition performance [1]. According to another source noise negatively affects performance in verbal tasks, like reading and spelling, and performance on speed tasks [2]. Noise is also prone to cause fatigue and headaches [3]. Noise is still related to the annoyance of both students and teachers. Chatter in the classroom is considered an annoying sound source. Teachers are more sensitive to noise than students and experience a higher level of stress. Females felt that noise caused them more stress than males [4].

It, therefore, seems to be beneficial if the noise level is low. To control the noise produced by students, inside the classroom, the teacher can resort to several classroom management strategies. The teacher can establish rules so that students know when they can talk and when they are supposed to be quiet and then reward students for adequate behavior by giving them a better grade, stars, points or smiley faces or showing their names in an honor board. A student's bad behavior can be punished by asking that student to leave the classroom or by giving her or him extra tasks to do or by keeping the student inside the classroom during recess [5]. However, none of this clearly shows to the students how much their behavior is disruptive. Perhaps, if students could perceive, in a quantitative way, how much their behavior is disruptive, then perhaps they would be more inclined to be quiet or to lower their voices. Our game was designed to test this hypothesis, as is further explained in Section 4.

Students are not the only ones negatively affected by a noisy classroom. Teachers, in consequence of the strain to their voices, may suffer health problems. Voice is one of the most important tools for a teacher because they have to talk for a long length of time and may also have to make themselves heard over a loud background noise. $62,7 \%$ of teachers are affected by voice problems [6]. Voice problems are more frequent in teachers than in other professions [7].

Voice problems can significantly affect a teacher. Teachers with frequent voice problems have decreased control and influence at work, low social support, poor job compensations, poor health and vitality perceptions and deficient job satisfaction [6]. Voice problems are also the cause behind lost days of work due to sick leave [8].

Voice problems are associated with the personality of the individual [9]. Teachers with voice problems tend to have a higher reactivity to stress. Still, if reactivity to stress is indeed a cause of voice problems, this personal characteristic may be difficult to change.

To ease or prevent voice problems the teacher can use a microphone for voice amplification. Adequate voice training, better acoustic conditions in the classroom and the absence of environmental irritants like dust or smoke are helpful. A fewer number of lessons will reduce the strain to the voice. Another solution is to reduce the number of children in the classroom as fewer children will produce less noise. 
Usually, the teacher cannot change the work schedule and also cannot decide how many children are in the classroom. However if all children are quiet, while the teacher is explaining something, the teacher will not have to talk so loud, thus reducing the strain on the vocal cords. Our game motivates children to keep quiet or lower their voices. In the next section some examples of persuasive technology are presented.

\section{Changing Behavior with Games}

Persuasive technology has already been successfully used to change people's behavior. Here are a few diverse examples: help children deal with bullying situations [10]; motivate people to recycle waste materials [11, 12]; encourage children to decrease energy consumption at home [13]; encourage healthy dietary behaviors in kindergarten children [14]; raise teenagers' oral health and dental hygiene awareness [15]; stimulate physical play [16]; help people quit smoking [17]; help elders take their medication on time [18]; improve engagement in science controversies and develop skills in evaluating evidence and forming arguments [19]; improve awareness of drugs abuse effects [20]; raise awareness about water scarcity [21]; improve workers' mental engagement in routine activities [22]; treat cockroach phobia [23]; incentive people to throw rubbish in a bin, instead of on the floor [24]; incentive people to obey the speed limit [25].

These examples show that there is great potential to alter people's behavior, not only in the classroom, but in many other situations.

In what particularly refers to influencing the amount of sound produced by the students while talking to each other, in [26] a sound level meter was used to monitor a free study period. An observer recorded the data from a position in the rear center of the room and wrote it on sheets of paper attached to a clipboard. If the students kept the sound level low, for ten minutes, they would receive two extra minutes for the gym period and a two minutes break to do whatever they wanted, before the beginning of the next ten minutes period. However, if the students became too noisy, during the ten minutes silent period, a whistle would be blown and the timer would be reset back. In [27], the authors resorted to an automated clown to show the children if the sound level was too high. The clown had five lights that simulated the jacket buttons, two lights that simulated the eyes, one light that simulated the nose and five lights that simulated the mouth. If the children kept the sound level low the clown's lights would turn on. James W. Groff patented an alarm that emits a sound when the classroom is too noisy [28].

\section{The Game}

Our game is a game that shows students, in real time, quantitatively and graphically, the amount of sound in the classroom. The game runs in a computer that is connected to a video projector or to an interactive whiteboard so that all students can see the output of the game. Sound is captured through a microphone connected to the computer where the game is running. The game is populated by characters that enjoy 
the silence. If the amount of sound the microphone is detecting is low the score increases. If the amount of sound the microphone is detecting is too high the score decreases and may even become negative.

The game's name is "The Castle of Count Pat". The characters of the game are Pat, a centuries old vampire, Pat's Cat and the Moon. The game begins with a story that explains the necessity of peace and quiet at Count Pat's Castle (Fig. 1). Count Pat does not like noise because he wants to sleep peacefully in his coffin. Count Pat's Cat likes silence because noise scares away the rats. It is difficult for Pat to adapt to nowadays noisy times so he took a decision: everyone who is making noise shall be turned into a vampire. If students want to keep their lives, they will have to keep quiet or at least lower their voices. The story is presented as a sequence of images. The teacher reads the story aloud to the students. To advance, the teacher presses the next button at the bottom of each image of the story. We chose this sort of interface because, this way, the teacher can present the story to the students at her or his desired speed. A video would make it more difficult to slow the pace of the story if some of the students had not understood it.

After the story in Fig. 1, the game starts. The teacher, together with the students, can choose a character to interact with: Count Pat (Fig. 2 (a)), Count Pat's Cat (Fig. 2 (b)) or the Moon (Fig. 2 (c)).

The sound wave is below Count Pat and the Moon. The frequency spectrum, after a Fourier transform is performed on the sound data, is integrated in the Cat's fur. At the bottom left corner of the game's interface the three available characters are presented. The teacher, or one of the students, can change the character by clicking on one of them. The other elements of the interface are: a volume bar that shows the amount of sound the microphone is detecting; the score; a button to end the game; and a button to pause the game.

Each character has three states. In state 1 all the characters are sleeping (Fig. 2). This is the best possible state. While in state 1 the score increases 0.2 points a second. The character remains in state 1 while the volume bar shows only its green section. The volume bar is divided in three sections. The leftmost section is green. The middle section is yellow. The rightmost section is red. If the volume bar shows the green and yellow sections, the character changes to state 2 . Here, the score increases 0.1 points a second. In state 2 Pat opens the coffin, the Cat stands up and the Moon awakes (Fig. 2 ). If the volume bar is showing the green, yellow and red sections the character changes to state 3 . This means the students are making too much noise. While the character is in state 3 the score decreases 0.1 points a second. If the students do not become quieter the score can turn negative. In the state 3 , the characters are wide awake and angry. Pat puts his hands over is hears, the Cat's fur stands on end and the Moon shows a displeased face (Fig. 2).

Previous tests were conducted, in a classroom, with the students and their teachers, to decide when the amount of sound detected by the microphone is too high in order to determine the green, yellow and red sections of the volume bar. We were told, by the teacher, when the noise was considered excessive. 
(1)

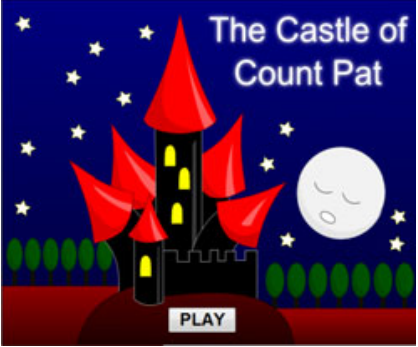

(3)

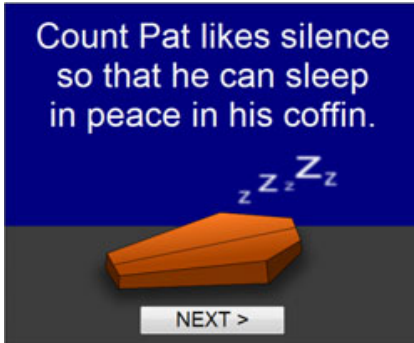

(5)

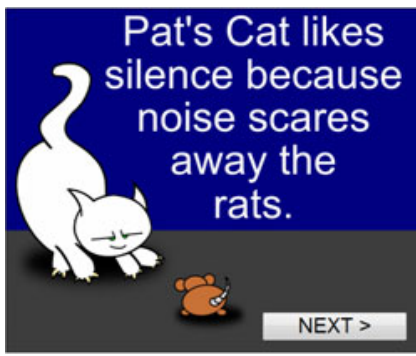

(7)

It is difficult for Pat adapting to nowadays noisy times...

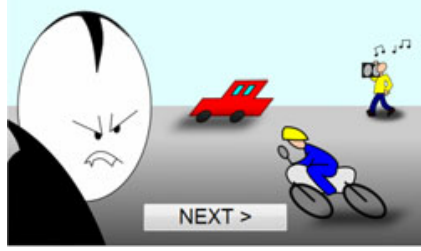

(9)

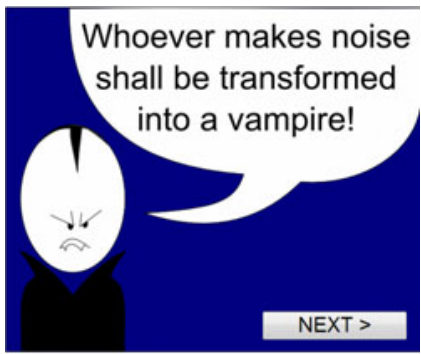

(2)

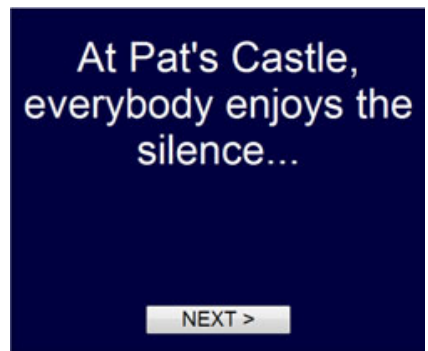

(4)

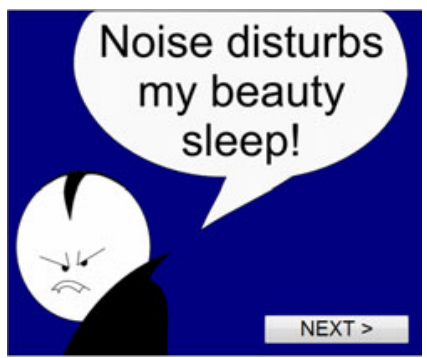

(6)

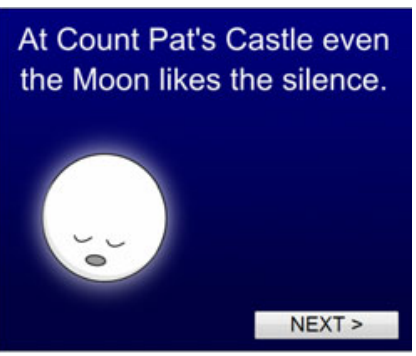

(8)

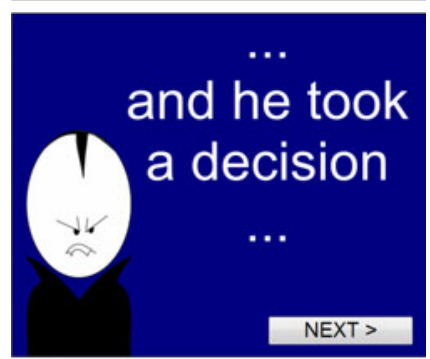

(10)

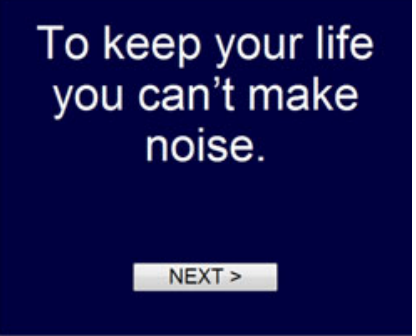

Fig. 1. The game begins with a story that explains why silence is necessary at Count Pat's Castle 
To determine the state of the character we calculated the average of the last 10 activity level values of the microphone. The activity level is the amount of sound the microphone is detecting. Values range from 0 , where no sound is detected, to 100, where very loud sound is detected. Each second the game collects 24 values of the microphone's activity level. We calculated the average of the last 10 activity level values because, if individual values were considered, the character would change between states too fast. At each second, the last computed average value is evaluated to determine how much to increase the score.

While the game is paused the score does not change. After the game ends the final score is displayed.

\section{State 1}

Low noise
State 2

Medium noise
State 3

High noise
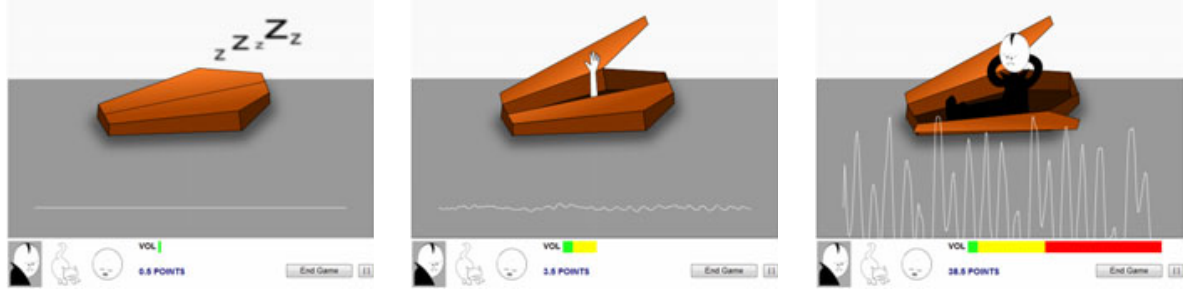

(a) Count Pat

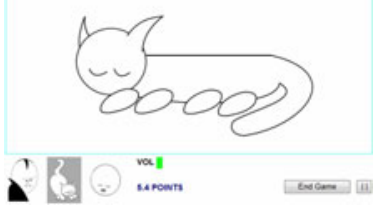

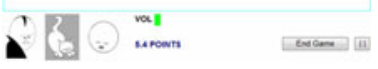

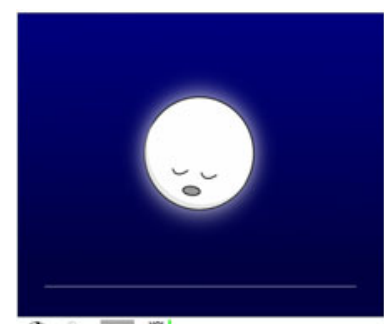

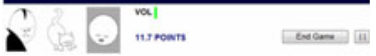
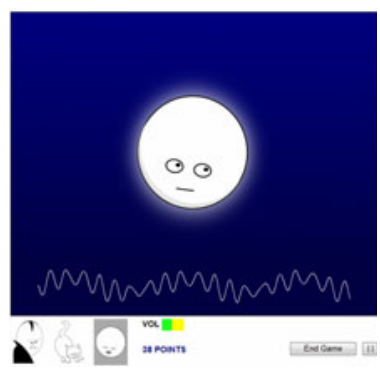

sers

(c) Moon
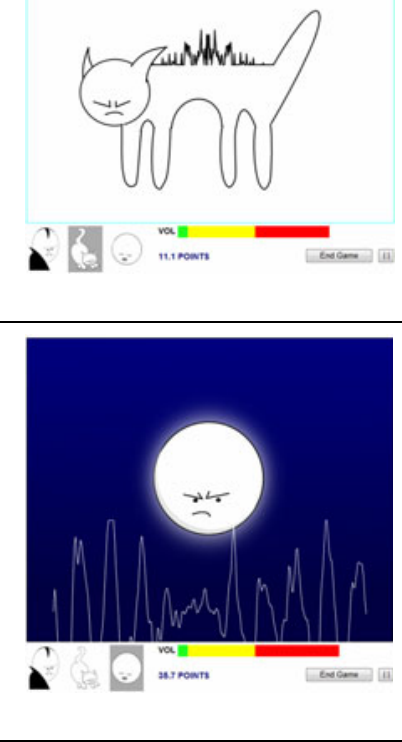

Fig. 2. The different states of the three characters 


\section{Assessment of the School Where the Game Was Tested}

The game's tests were conducted in a school that is both an elementary and a secondary school. To evaluate the school's initial situation we conducted a survey to 60 of the school's 150 teachers. The teachers were questioned, with a paper survey, at the staff room, a place where teachers can rest. The survey was previously tested and was anonymous, but we were present at the staff room in case teachers had any doubt about the survey.

Through the survey we tried to determine if noise, caused by the students, was a problem. $78,3 \%$ of the inquired teachers agreed or strongly agreed that students make too much noise and that negatively influences their learning (Fig. 3).

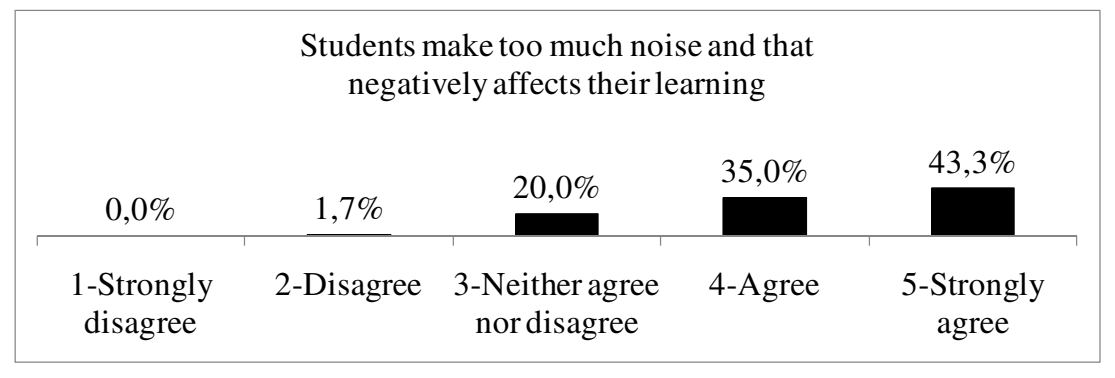

Fig. 3. Do teachers think that students make too much noise?

Almost all teachers agreed, or strongly agreed that when the students are making too much noise it is more difficult for them to teach the class (Fig. 4).

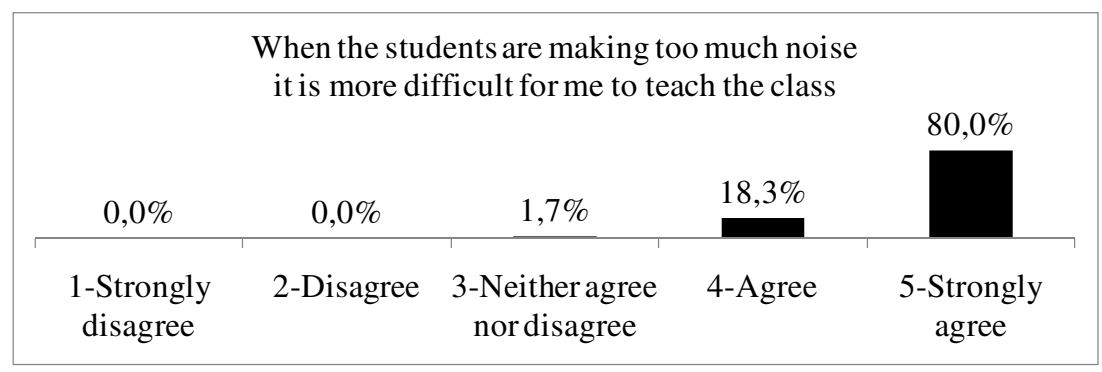

Fig. 4. Do teachers find it more difficult to teach the class when the students are making too much noise?

$45 \%$ of the teachers reported voice problems like a hoarse voice, pains, vocal cord nodules or polyps or even being completely aphonic. Two of the enquired teachers underwent surgery because of their voice problems. One teacher afflicted by voice problems mentioned that those voice problems resulted in a depression and another reported feeling extremely tired. 
Even though almost half of the enquired teachers have voice problems, $45 \%$ is not a percentage as high as the one found in [6].

We asked teachers if they thought that students were aware that talking while the teacher is explaining something negatively affects their learning (Fig. 5). 25\% of the enquired teachers strongly disagree or simply disagree that students are aware of it. $35 \%$ neither agree nor disagree. $40 \%$ agree, or strongly agree, that students are conscious that their behavior is negatively affecting their learning.

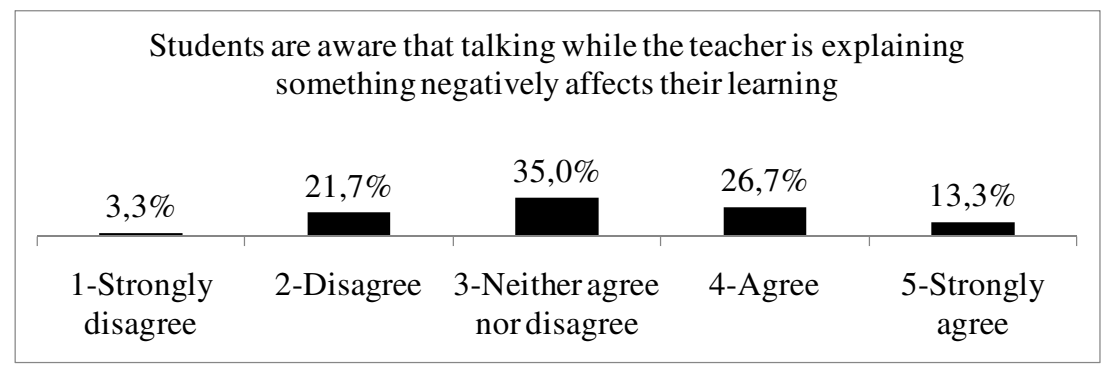

Fig. 5. Do teachers think that students are aware that talking while the teacher is explaining something negatively affects their learning?

When we asked the teachers if they thought that showing the students how much noise they are making would cause them to be quieter, $48,3 \%$ of the teachers agreed or strongly agreed this would work (Fig. 6). 36,7\% of the teachers think that showing the students how much noise they are making would have no effect and $15 \%$ think that students would make even more noise. So, even though $40 \%$ of the enquired teachers believe that students are aware that they make too much noise in the classroom, 48,3\% of the teachers believe that showing the students how much noise they are making is an extra reinforcement that might have some positive effect.

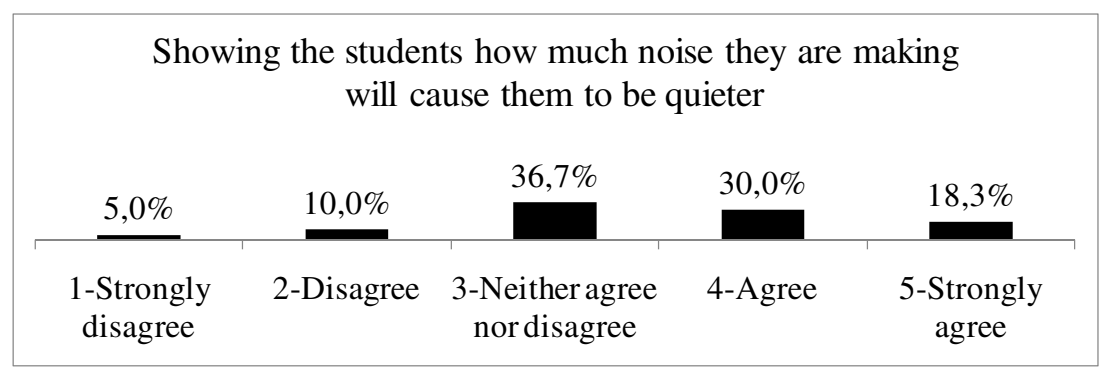

Fig. 6. Do teachers think that showing the students how much noise they are making will cause them to be quieter?

We tried to determine if the teachers' views about noise in the classroom were similar to the students' views. To this effect we enquired 81 students from 4 classes. These classes are the same classes where the game was tested. The survey was anonymous and previously tested. Only $34,5 \%$ of the inquired students think that their 
colleagues make too much noise in the classroom (Fig. 7). In contrast, 78,3\% of the inquired teachers consider the noise caused by the students excessive. So, the inquired students and teachers have different views and perhaps students do not completely realize that, according to the teachers, they are too noisy.

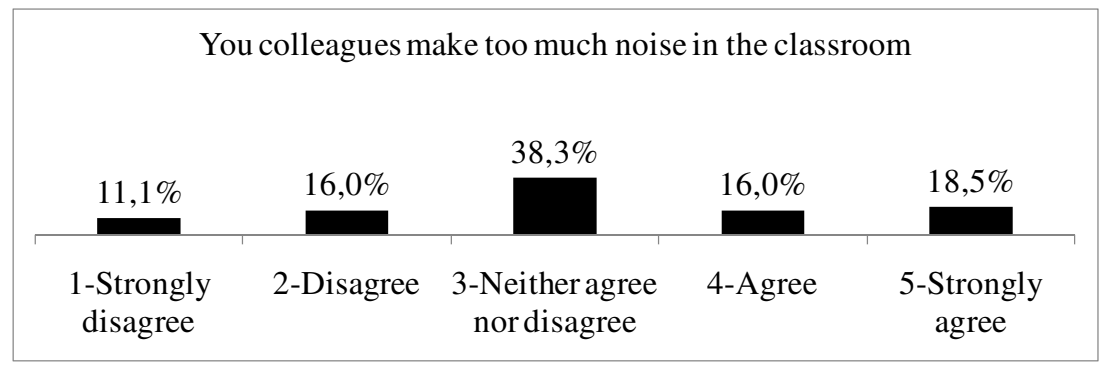

Fig. 7. Do students think their colleagues make too much noise in the classroom?

However, $61,1 \%$ of the students agree or strongly agree that if students are quiet, the grades will be better (Fig. 8). Therefore, most students and teachers agree that a quieter class will result in better grades.

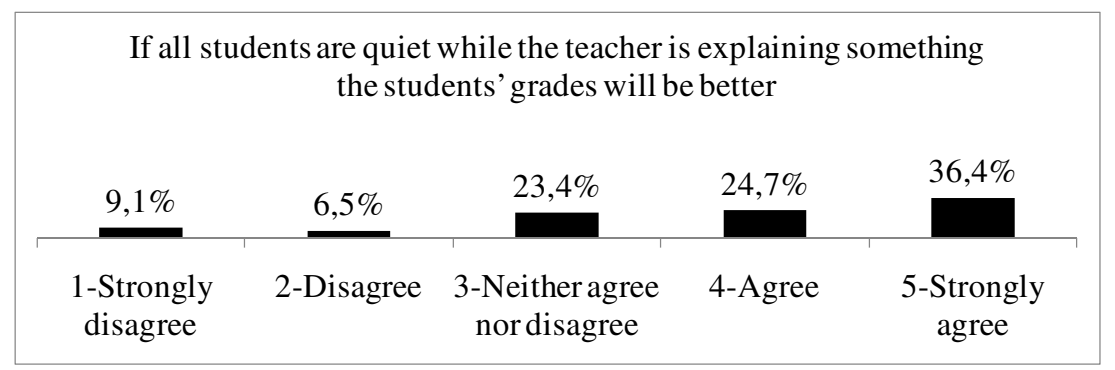

Fig. 8. Do students think that if they are quiet the grades will improve?

\section{Testing the Game}

Our game was tested in four classes of an elementary and secondary school. We shall refer to the classes as classes A, B, C and D. All of them were practical classes of Informatics. The classes' duration was 90 minutes. The number of students, grade, age average and age range of each class can be observed it Table 1.

Table 1. Composition of the classes where the game was tested

\begin{tabular}{|c|c|c|c|c|c|}
\hline Class & Teacher & Number of students & Grade & Age average & Age range \\
\hline A & X & 18 & 8 & 14.6 & $12-16$ \\
\hline B & Y & 27 & 9 & 14 & $13-17$ \\
\hline C & X & 21 & 9 & 15.5 & $15-17$ \\
\hline D & X & 15 & 12 & 17 & $16-18$ \\
\hline
\end{tabular}


Before any tests were conducted we interviewed the teachers of the classes to determine what they thought about them. Among teacher X's classes, class D was expected to be the quieter one. Class D's students were described by the teacher as being mature and hard working. Class A and class C's students were younger and the teacher expected them to be noisier. Class A was considered problematic because, even though it had only 18 students, many of them were repeating that grade. The teacher told us she left that class often feeling tired and with a hoarse voice.

Teacher Y expected class B to be noisy because this was the class with the greatest number of students and also because the students were still very immature.

Both teachers told us that students often loose conscience of how loud they are talking when they are engaged in group work.

First, we computed the average amount of sound detected by the microphone in all the classes without the game (Fig. 9).

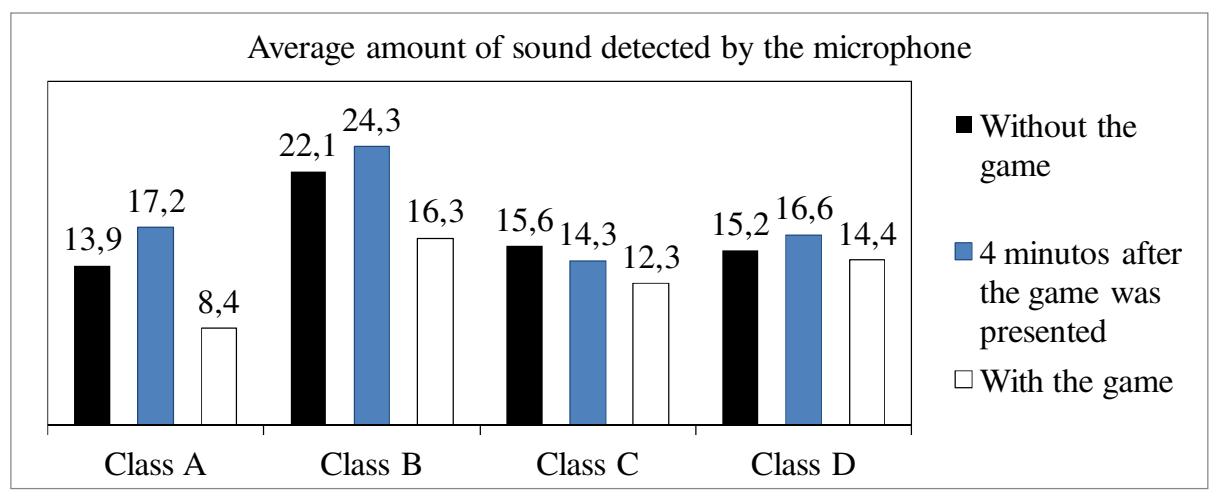

Fig. 9. Average amount of sound detected by the microphone with and without the game

Teacher X told us she was surprised that class A was the least noisy of her classes. The teacher attributed the greater fatigue, felt in class A, to the extra effort she had to make to motivate the students.

In the second lesson the game was tested. A video projector was used to show the game to all students (Fig. 10). The classroom had two whiteboards. We projected the game on the rightmost whiteboard. The teacher used the leftmost whiteboard when necessary. During the test of the game none of the teachers needed to show slides to the students. If this was the case, then a second video projector would be necessary.

At the beginning of the class the game was explained to the students. The students were told that the game would be tested is several classes and that the quieter class would receive a mystery gift. The three characters were shown to the students and they chose one of them. Afterwards, the lesson continued as usual. 


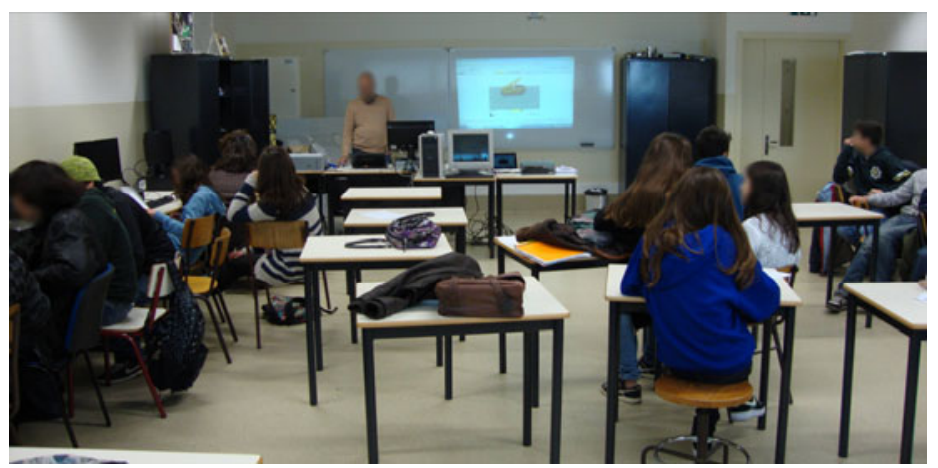

Fig. 10. Class while the game is being tested

In all of the classes the amount of sound detected by the microphone decreased (Table 2). In class A there was a 39,6\% decrease. This was the highest reduction of all the classes.

Table 2. Average amount of sound detected by the microphone during a first lesson without the game and during a second lesson with the game

\begin{tabular}{|c|c|c|c|}
\hline \multirow{2}{*}{ Class } & \multicolumn{2}{|c|}{\begin{tabular}{c}
\multirow{2}{*}{ Average amount of sound detected by the microphone } \\
With the game
\end{tabular}} & \\
\cline { 2 - 3 } & Without the game & 8,4 & $39,6 \%$ \\
\hline A & 13,9 & 16,3 & $26,2 \%$ \\
\hline B & 22,1 & 12,3 & $21,2 \%$ \\
\hline C & 15,6 & 14,4 & $5,3 \%$ \\
\hline D & 15,2 & \\
\hline
\end{tabular}

Class D was the class where the use of the game resulted in the smallest decrease. The average amount of sound detected by the microphone decreased only $5,3 \%$. In classes $B$ and $C$ there was a decrease of $26,2 \%$ and $21,2 \%$ respectively.

Also, in all of the classes, except in class $\mathrm{C}$, the average amount of sound detected by the microphone, during the 4 minutes after the game was explained to the students, was higher than in the first lesson without the game (Fig. 9). This happened because, at first, the game captivated the students' curiosity and they tried to test it. Some students would raise their voices or whistle to see how the game reacted. They asked how much the score would increase, when they were quiet, and commented on the changes in the sound wave or in the frequency spectrum according to the different types of sounds produced.

Gradually, students turned their attention to their tasks. However the game was not forgotten. Throughout the class, students would often look at the projection to check the score. If one of the students was talking too loud, another one would usually ask her or him to lower her or his voice. Some students asked us what the score in the other classes was. For these students, competition with the other classes seems to be a motivation. Other students tried to set goals. Those students would turn to the rest of the class and say that they had to increase a certain number of points till the end of the 
lesson and urged the others to be quiet. This type of peer pressure was more frequent in classes $\mathrm{A}$ and $\mathrm{B}$ than in classes $\mathrm{C}$ and $\mathrm{D}$.

At the end of the lesson, where the game was tested, the students filled an anonymous survey that was previously tested.

In the survey, we asked the students if the class was quieter, during the use of the game (Fig. 11). In classes A, B and C most of the students agreed or strongly agreed that the classroom was quieter during the use of the game. These results are consistent with the results presented in Fig. 9. Class A is the class where more students agreed or strongly agreed that the class was quieter during the use of the game. The average amount of sound detected by the microphone decreased $39,6 \%$ in this class and this was perhaps easily noticed by most of the students. In class D, only $42,9 \%$ of the students agreed or strongly agreed that the class was quieter during the use of the game. This happened, probably, because the average amount of sound detected by the microphone decreased only 5,3\% and this was hardly noticed by the students.

During the use of the game the class was quieter

1 - Strongly disagree; 2 - Disagree; 3 - Neither agree or disagree; 4 - Agree; 5 - Strongly Agree
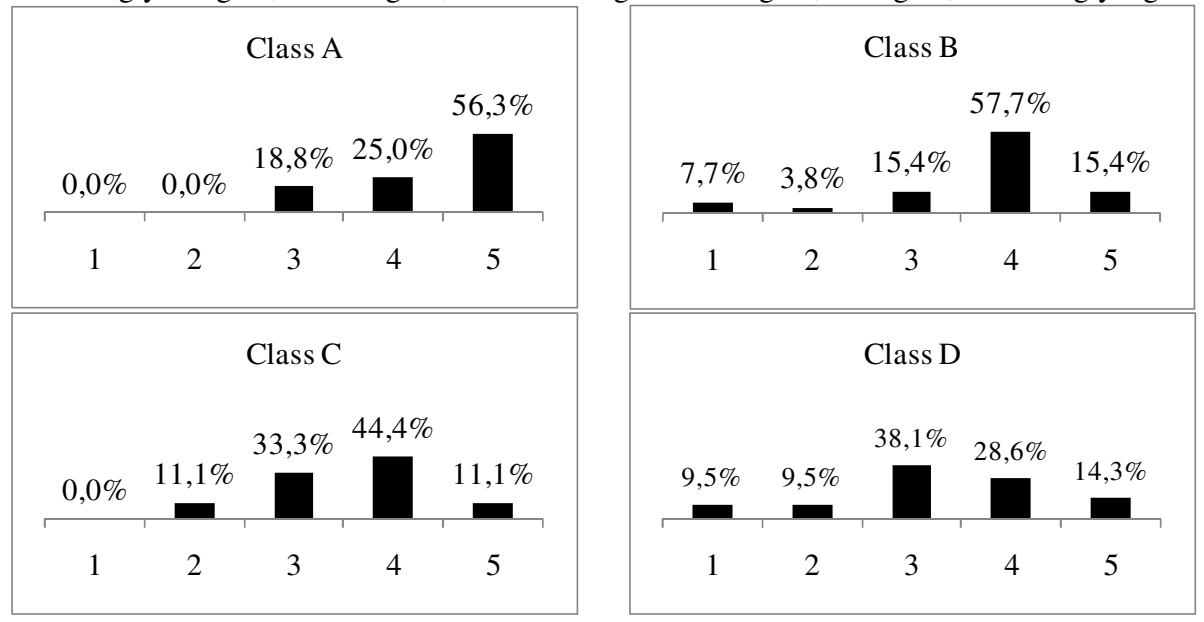

Fig. 11. Was the class quieter during the use of the game?

We wondered if the game would cause the students to pay more attention to the class. The game could also have the opposite effect. If the students spent a lot of time looking at the game that could reduce the time they spent listening to the teacher or working in their tasks. So, we asked the students if the game helped them pay more attention to the lesson (Fig. 12). Only in class A did most of the students agreed or strongly agreed that the game helped them pay more attention to the class. In classes B, C and D the answer "Neither agree or disagree" was the most chosen one. We interviewed the teachers of classes A, B, C and D and they noticed no visible change in the students' attention to the lesson, even in class A. This seems to indicate that the game did not significantly influence the attention of the students to the lesson. 
The game helped me pay more attention to the lesson

1 - Strongly disagree; 2 - Disagree; 3 - Neither agree or disagree; 4 - Agree; 5 - Strongly Agree
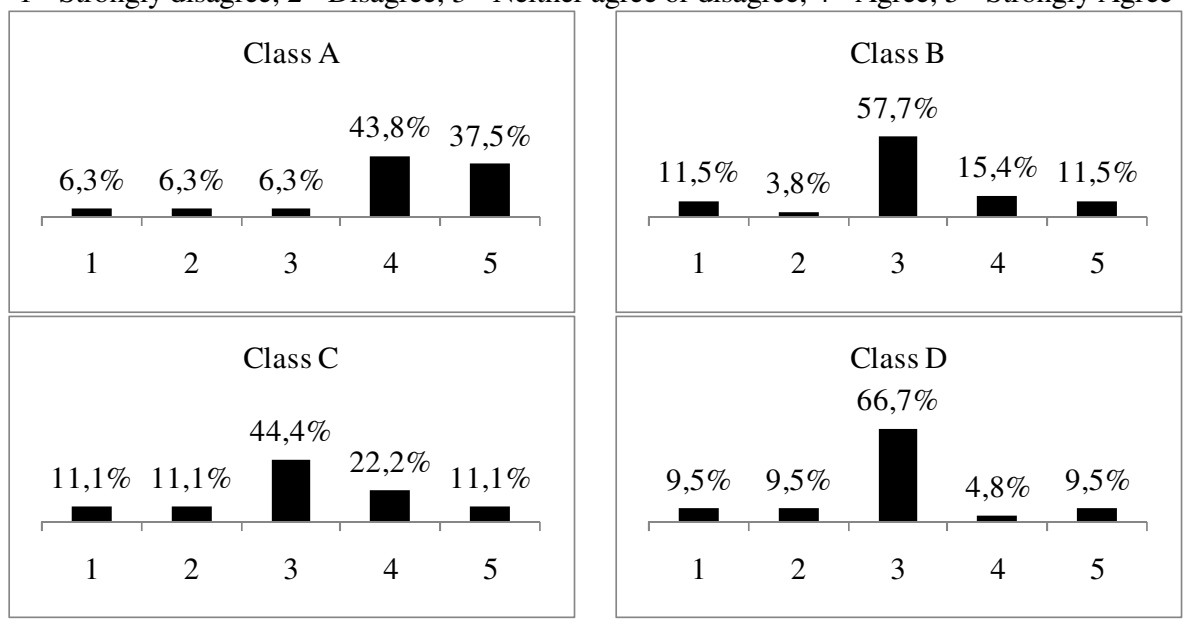

Fig. 12. Did the game helped students pay more attention to the lesson?

To make clear if the game decreased the students' attention to the teacher we included another question in the survey. We asked the students if the game distracted them from what the teacher was explaining (Fig. 13).

The game distracted me from what teacher was explaining 1 - Strongly disagree; 2 - Disagree; 3 - Neither agree or disagree; 4 - Agree; 5 - Strongly Agree

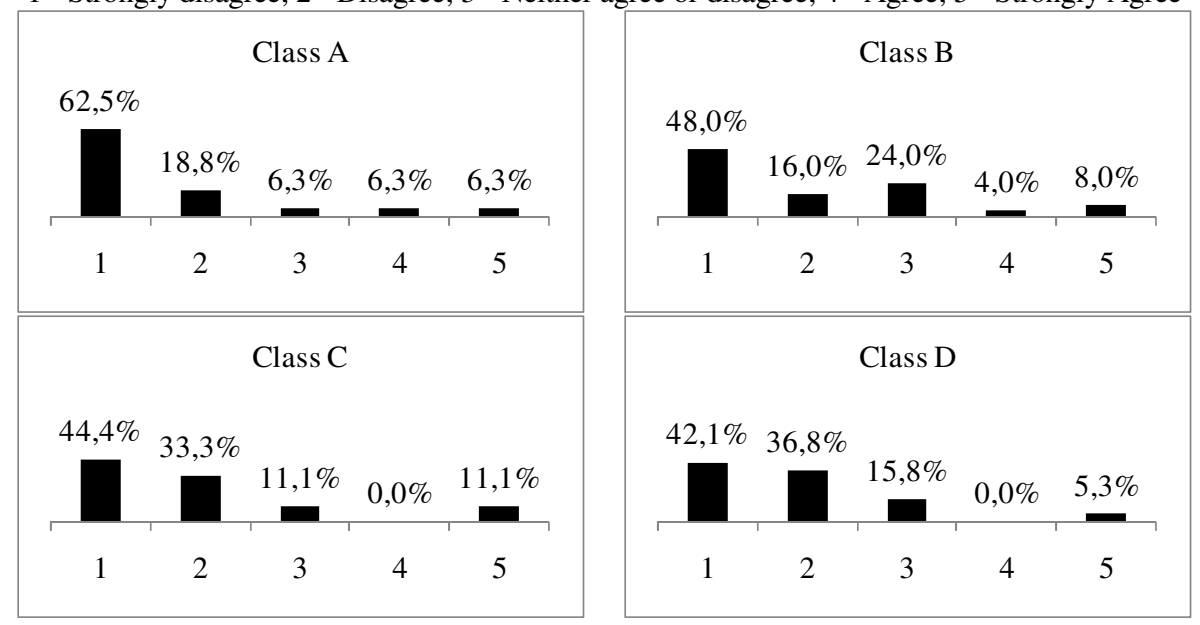

Fig. 13. Did the game distract the students from what the teacher was explaining? 
In all the classes, the attention to what the teacher was explaining of most students was not negatively affected by the game. The percentage of students that agreed or strongly agreed that the game distracted them is quite small in all the classes. This indicates that even though the game did not cause the students to pay more attention it also did not cause the opposite effect. As the game does not measure the attention of the students to the lesson we consider that these results are not surprising.

In the survey we asked the students if it was important for them to obtain a good score in the game (Fig. 14). In classes A and B, 75,1\% and 69,2\% of the students considered it was important for them to obtain a good score in the game. This means a high percentage of the students were trying to stay quiet or, at least, lower their voices. That is perhaps one of the reasons why the average amount of sound detected by the microphone greatly decreased in both these classes. In class $C$ more than half the students were interested in a good score and that seems to have contributed to a decrease of the average amount of sound detected by the microphone during the use of the game. Class D is the class with the lowest percentage of students interested in a good score. If there was a way to increase class D's interest in a good score, perhaps the average amount of sound detected by the microphone would have decreased more.

It was important for me to obtain a good score in the game

1 - Strongly disagree; 2 - Disagree; 3 - Neither agree or disagree; 4 - Agree; 5 - Strongly Agree

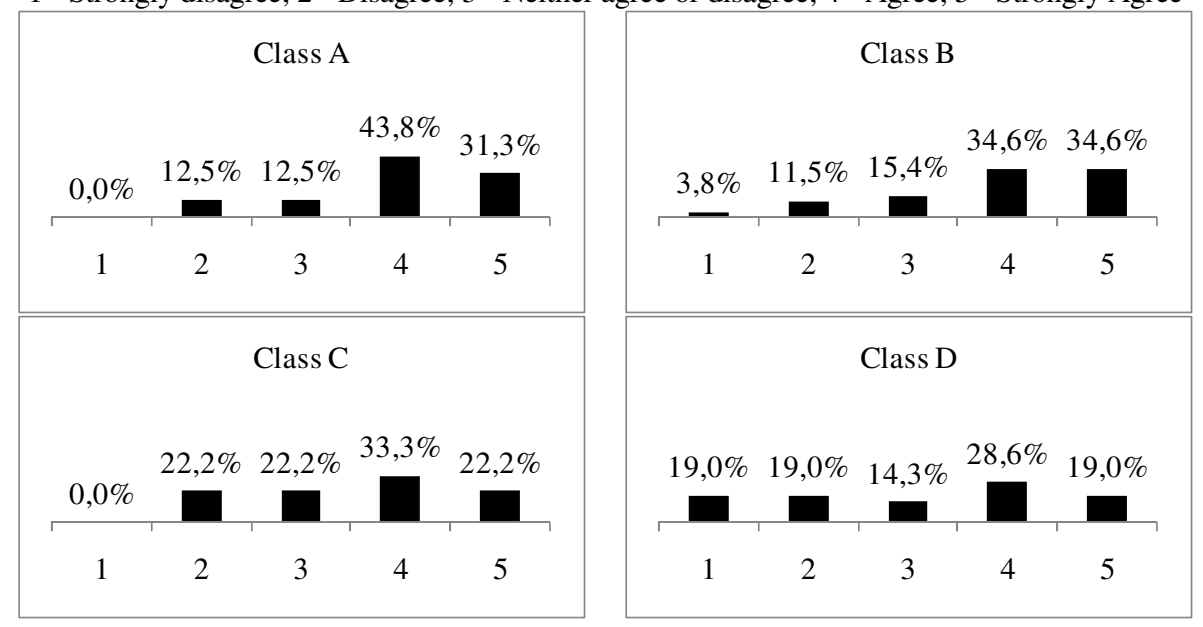

Fig. 14. Was it important for students to obtain a good score in the game?

We were also interested in knowing if the students liked the game's characters (Fig. 15). If the students liked the game's characters then maybe they could create some sort of empathy with the characters and that would motivate the students to please the character by staying quiet or lowering their voice level. In classes A and B most of the students agree or strongly agree that they liked the game's characters. In class A, the percentage of students that strongly liked the game's characters is higher than in class B, though. In class C $44,4 \%$ of the students agreed or strongly agreed that they liked the game's characters. In class D we obtained the worst results. $35 \%$ of 
the students strongly disliked the game's characters and 10\% didn't like them. Many of these students complained, in the survey, that the characters were too childish and, therefore, not appropriate for their age. Indeed class D is the class where the age average is higher. This seems to indicate that a different approach should have been used with these older students. Perhaps, if the students liked the characters they would feel more inclined to please them and stay quiet.

I liked the game's characters

1 - Strongly disagree; 2 - Disagree; 3 - Neither agree or disagree; 4 - Agree; 5 - Strongly Agree

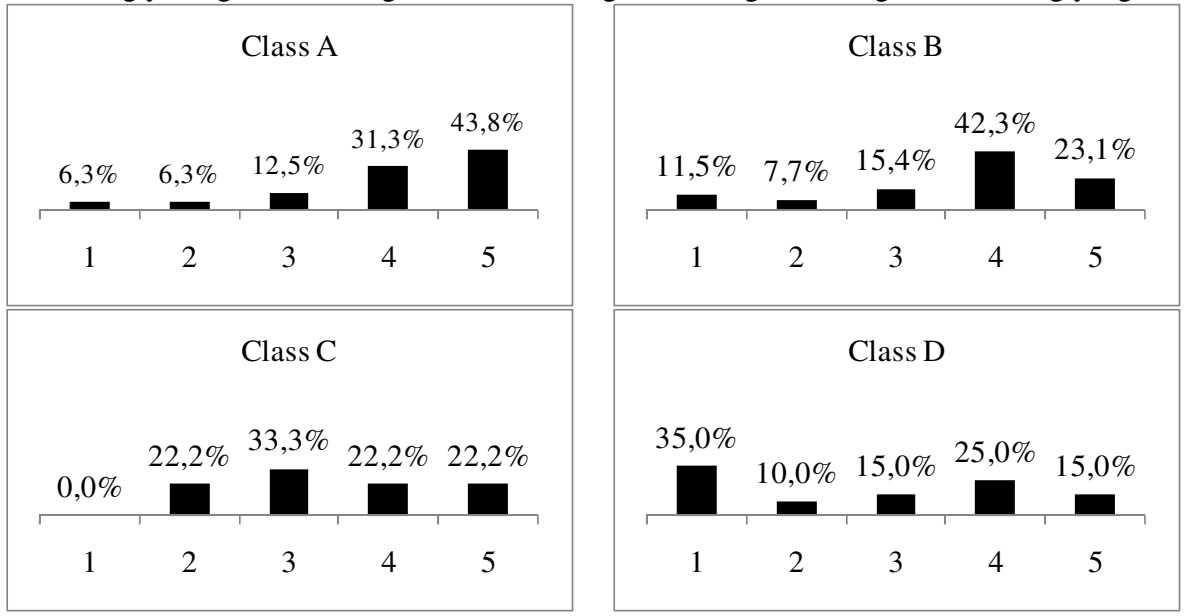

Fig. 15. Did students like the game's characters?

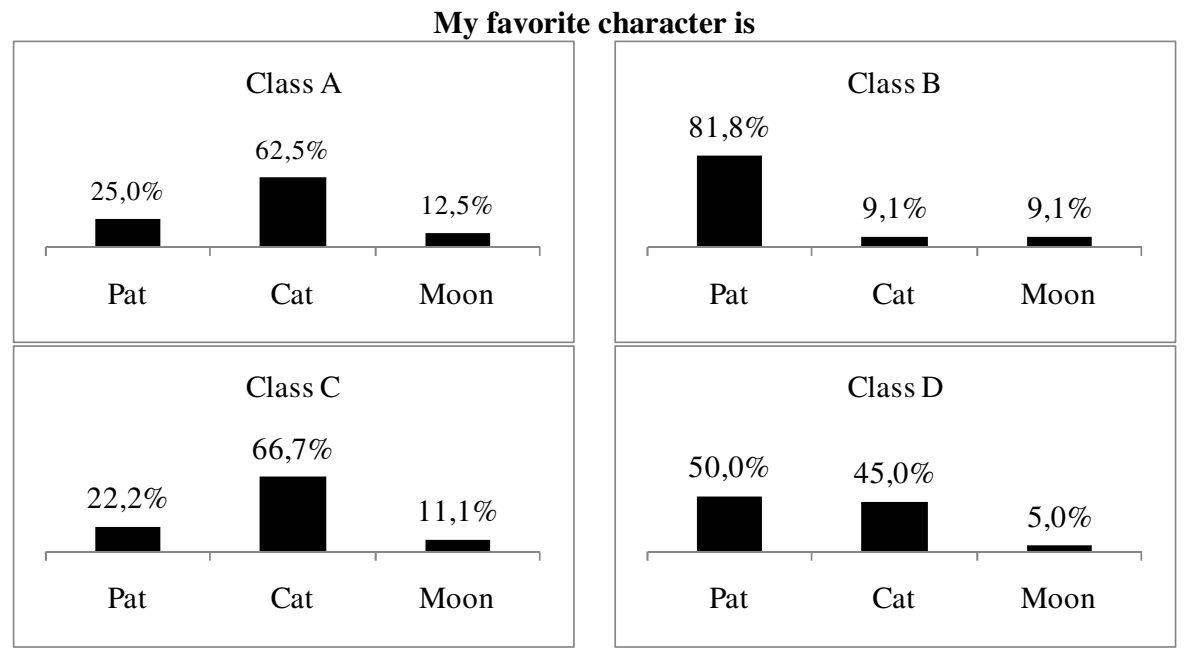

Fig. 16. Students' favorite characters 
In classes $A$ and $C$ the favorite character was the Cat (Fig. 16). Some students told us that they found funny how the sound spectrum was integrated in the Cat's fur and how the Cat stood up when she was angry. In classes B and D the favorite character was Count Pat. The Moon was the least liked character in all the classes. Some students found the Moon too dark and dull. Others said that with Pat and with the Cat it was easier to perceive when the character was happy or angry.

\section{Conclusions and Future Work}

In this paper we investigated if the quantitative and graphical perception of sound, by students, in a classroom, can affect how noisy these students are. A survey was conducted to 60 teachers, of an elementary and secondary school, to find out if they considered that noise, caused by the students talking to each other in the classroom, was a problem. $78,3 \%$ of the inquired teachers agreed or strongly agreed that students make too much noise and that negatively affects their learning. Besides, 98,3\% of the inquired teachers thought that when the students are making too much noise it is more difficult to teach the class. Only $34,5 \%$ of the inquired 81 students agreed or strongly agreed that their colleagues make too much noise in the classroom.

The teacher can tell the students that they are speaking too loud, but this does not show then, in a quantitative way, how much noise they are making. Our hypothesis was that, if students are more aware of how much noise they are making this would cause them to be quieter. To test this hypothesis we developed a game that shows students, in real time, the amount of sound a microphone is detecting in the classroom. The lower the amount of sound the microphone is detecting, the more points the students accumulate. The game shows the sound wave or the frequency spectrum, after a Fourier transform is performed on the sound data. The interface also integrates a character and a volume bar. The character changes state and the volume bar changes size according to the microphone's activity level. A video projector was used so that all students could see the output of the game.

The game was tested in classes A, B, C and D. The average amount of sound detected by the microphone was computed during a first lesson, for each class, without the game. Afterwards, during a second lesson, the average amount of sound detected by the microphone was computed again while using the game. The average amount of sound detected by the microphone decreased $39,6 \%, 26,2 \%, 21,2 \%$ and $5,3 \%$ in, respectively, classes A, B, C and D. The age average of classes A, B, C and $\mathrm{D}$ is 14,6 years old, 14 years old, 15,5 years and 17 years old respectively. Therefore, the game performed better, in the reduction of the average amount of sound detected by the microphone, with the younger students. Future work will have to be conducted to test if showing the students the amount of sound detected by the microphone in the classroom is a strategy that works better with younger students. Several students in class D complained that the game's characters were too childish. If the game's characters had been more adequate to these students then perhaps they would have felt more inclined to be quieter or to lower their voices. Nevertheless, even in class D, the average amount of sound detected by the microphone decreased 5,3\%.

The influence of the game in the students' attention to what the teacher was explaining was also tested. We interviewed the teachers of the classes and conducted 
an anonymous survey to the students. The answers show that the game did not negatively influence the attention of the students in class.

Acknowledgements. This work was partly funded by FCT/MCTES, through grant SFRH/BD/61085/2009, and by Centro de Informática e Tecnologias da Informação (CITI/FCT/UNL)-2011-2012 through grant PEst-OE/EEI/UI0527/2011. The authors thank everyone at IMG-CITI.

\section{References}

1. Nelson, P., Kohnert, K., Sabur, S.: Classroom Noise and Children Learning Through a Second Language. In: Language, Speech, and Hearing Services in Schools, vol. 36, pp. 219-229 (2005)

2. Shield, B., Dockrell, J.: The Effects of noise on the attainments and cognitive performance of primary school children: executive summary. Report for the UK's Department of Health (2002)

3. Walinder, R., Gunnarsson, K., Runeson, R., Smedje, G.: Physiological and psychological stress reactions in relation to classroom noise. Scandinavian Journal of Work, Environment \& Health 33(4), 260-266 (2007)

4. Enmarker, I., Boman, E.: Noise annoyance responses of middle school pupils and teachers. Journal of Environmental Psychology 24(4), 527-536 (2004)

5. Arends, R.I.: Aprender a Ensinar. Editora McGraw-Hill de Portugal, Amadora (1995)

6. Alvear, R.M.B., Martínez-Arquero, G., Barón, F.J., Hernández-Mendo, A.: An Interdisciplinary Approach to Teachers' Voice Disorders and Psychosocial Working Conditions. International Journal of Phoniatrics, Speech Therapy and Communications Pathology 62(1-2) (2010)

7. Roy, N., Merrill, R.M., Thibeault, S., Gray, S.D., Smith, E.M.: Voice Disorders in Teachers and the General Population - Effects on Work Performance, Attendance, and Future Career Choices. Journal of Speech, Language, and Hearing Research 47(3), 542551 (2004)

8. Nerrière, E., Vercambre, M., Gilbert, F., Kovess-Masféty, V.: Voice disorders and mental health in teachers: a cross-sectional nationwide study. BMC Public Health 9, 370 (2009)

9. Gassull, C., Casanova, C., Botey, Q., Amador, M.: The Impact of the Reactivity to Stress in Teachers with Voice Problems. International Journal of Phoniatrics, Speech Therapy and Communications Pathology 62(1-2), 35-39 (2010)

10. Hall, L., Jones, S., Paiva, A., Aylett, R.: FearNot!: providing children with strategies to cope with bullying. In: Proceedings of the 8th International Conference on Interaction Design and Children, pp. 276-277. ACM, New York (2009)

11. Lobo, P., Romão, T., Dias, E.A., Danado, J.C.: A Framework to Develop Persuasive Smart Environments. In: Tscheligi, M., Ruyter, B., Markopoulus, P., Wichert, R., Mirlacher, T., Meschterjakov, A., Reitberger, W. (eds.) Proceedings of the European Conference on Ambient Intelligence, pp. 225-234. Springer, Heidelberg (2009)

12. Bottle Bank Arcade Machine, http://www. thefuntheory.com/bottle-bankarcade-machine

13. Gustafsson, A., Bång, M., Svahn, M.: Power explorer: a casual game style for encouraging long term behavior change among teenagers. In: Proceedings of the International Conference on Advances in Computer Entertainment, pp. 182-189. ACM, New York (2009) 
14. Lin, T., Chang, K., Liu, S., Chu, H.: A persuasive game to encourage healthy dietary behaviors of young children. Demo Paper \& Adjunct Proceedings of the 8th International Conference on Ubiquitous Computing (2006)

15. Soler, C., Zacarías, A., Lucero, A.: Molarcropolis: a mobile persuasive game to raise oral health and dental hygiene awareness. In: Proceedings of the International Conference on Advances in Computer Enterntainment Technology, pp. 388-391. ACM, New York (2009)

16. Bekker, T., Sturm, J., Eggen, B.: Designing playful interactions for social interaction and physical play. Personal and Ubiquitous Computing 14(5), 385-396 (2010)

17. Khaled, R., Barr, P., Biddle, R., Fischer, R., Noble, J.: Game design strategies for collectivist persuasion. In: Spencer, S.N. (ed.) Proceedings of the 2009 ACM SIGGRAPH Symposium on Video Games, pp. 31-38. ACM, New York (2009)

18. Oliveira, R., Cherubini, M., Oliver, N.: MoviPill: improving medication compliance for elders using a mobile persuasive social game. In: Proceedings of the 12th ACM International Conference on Ubiquitous Computing, pp. 251-260. ACM, New York (2010)

19. Rosenbaum, E., Klopfer, E., Boughner, B., Rosenheck, L.: Engaging students in science controversy through an augmented reality role-playing game. In: Chinn, C.A., Erkens, G., Puntambekar, S. (eds.) Proceedings of the 8th International Conference on Computer Supported Collaborative Learning, pp. 612-614. International Society of the Learning Sciences (2007)

20. Gamberini, L., Breda, L., Grassi, A.: VIDEODOPE: applying persuasive technology to improve awareness of drugs abuse effects. In: Shumaker, R. (ed.) HCII 2007. LNCS, vol. 4563, pp. 633-641. Springer, Heidelberg (2007)

21. Hirsch, T.: Water wars: designing a civic game about water scarcity. In: Proceedings of the 8th ACM Conference on Designing Interactive Systems, pp. 340-343. ACM, New York (2010)

22. Shastri, D., Fujiki, Y., Buffington, R., Tsiamyrtzis, P., Pavlidis, I.: O job can you return my mojo: improving human engagement and enjoyment in routine activities. In: Proceedings of the 28th International Conference on Human Factors in Computing Systems, pp. 2491-2498. ACM, New York (2010)

23. Botella, C., Breton-López, J., Quero, S., Baños, R.M., García-Palacios, A., Zaragoza, I., Alcaniz, M.: Treating cockroach phobia using a serious game on a mobile phone and augmented reality exposure: A single case study. Computers in Human Behavior 27(1) (2011)

24. The World's Deepest Bin, http: / / www. thefuntheory. com/worlds-deepest-bin

25. The Speed Camera Lottery, http: / / www. thefuntheory.com/speed-camera-lottery-0

26. Schmidt, G.W., Ulrich, R.E.: Effects of group contingent events upon classroom noise. Journal of Applied Behavior Analysis 2(3), 171-179 (1969)

27. Strang, H.R., George, J.R.: Clowning around to stop clowning around: a brief report on an automated approach to monitor, record, and control classroom noise. Journal of Applied Behavior Analysis 8(4), 471-474 (1975)

28. Groff, J.W.: Tamperproof classroom noise alarm. United States Patent, Patent number: 4654642 (Filing date October 18, 1985), Issue date: (March 31, 1987) 